\title{
Effects and mechanisms of grain refinement in aluminium alloys
}

\author{
K T KASHYAP* and T CHANDRASHEKAR ${ }^{\dagger}$ \\ Central Laboratory, Foundry and Forge Division, Hindustan Aeronautics Ltd., Bangalore 560 017, India \\ ${ }^{\dagger}$ Department of Mechanical Engineering, M.S. Ramaiah Institute of Technology, Bangalore 560 054, India
}

MS received 9 April 2001; revised 11 June 2001

\begin{abstract}
Grain refinement plays a crucial role in improving characteristics and properties of cast and wrought aluminium alloys. Generally Al-Ti and Al-Ti-B master alloys are added to the aluminium alloys to grain refine the solidified product. The mechanism of grain refinement is of considerable controversy in the scientific literature. The nucleant effects i.e. which particle and its characteristics nucleate $\alpha$-Al, has been the subject of intensive research. Lately the solute effect i.e. the effect of dissolved titanium on grain refinement, has come into forefront of grain refinement research. The present paper attempts to review the literature on the nucleant effects and solute effects on grain refinement and addresses the importance of dissolved titanium in promoting nucleation of $\alpha$-Al on nucleant particles.
\end{abstract}

Keywords. Grain refinement; nucleant effects; solute effects; Al-Ti-B master alloy.

\section{Introduction}

Grain refinement plays a vital role in cast and wrought aluminum alloys. There are number of reasons why the control of grain size is important in semi continuously cast alloys. Firstly, reduced mechanical properties have been noted in plate products for structural application when a uniform as cast grain size is not achieved (Granger and Liu 1983; Labarri et al 1987). Twinned columnar grains have been reported to reduce fabricability, yield strength and tensile elongation to fracture. Secondly, a coarse grained structure may result in a variety of surface defects in alloys used in rolled or extruded form for architectural applications (Granger 1985). Thirdly, hot cracking in the shell zone of a d.c. cast ingot is more severe if the grain structure is not equiaxed. An equiaxed structure allows a higher casting rate to be achieved before hot cracking is produced.

Apart from wrought alloys grain refinement has several benefits in cast alloys like improved mechanical properties that are uniform throughout the casting, distribution of second phase and microporosity on a fine scale, better feeding to eliminate shrinkage porosity, improved ability to achieve a uniform anodized surface, better strength and fatigue life (Apelian et al 1984; McCartney 1989).

Grain refinement is achieved through the addition of $\mathrm{Al}-\mathrm{Ti}$ master alloy and/or $\mathrm{Al}-5 \% \mathrm{Ti}-1 \% \mathrm{~B}$ master alloy in a waffle form. The addition rate is $1 \mathrm{~kg} / 1000 \mathrm{~kg}$ giving Ti and B additions of $0.005 \%$ and $0.001 \%$ respectively. Such an addition level would typically produce an equiaxed

\footnotetext{
*Author for correspondence
}

grain size of $100-150 \mu \mathrm{m}$ in a small d.c. cast ingot of commercial purity aluminum.

The main objective of the present review is to summarize: (i) the theoretical concepts behind nucleation and growth processes driving the grain refinement, (ii) the nucleant effects in refinement, and (iii) the important part of refinement, i.e. solute effects in refinement.

\subsection{Nucleation}

Grain refinement can be understood to be directly related to the nucleation and growth process of aluminum grains. This is based on the nucleation ideas of Volmer and Weber (1925). The theory involves homogeneous and heterogeneous nucleation. In a pure metal solidifying, the critical nucleus size for survival is given by

$$
r_{\mathrm{homogeneous}}^{*}=\frac{-2 \gamma_{\mathrm{sL}}}{\Delta G_{\mathrm{v}}} .
$$

The free energy barrier is given by

$$
\Delta G_{\mathrm{homogeneous}}^{*}=\frac{16 \pi \gamma_{\mathrm{sL}}^{3}}{3 \Delta G_{\mathrm{v}}^{2}},
$$

where, $\gamma_{\mathrm{sL}}$ is the interface surface energy of a solid-liquid interface in $\mathrm{J} / \mathrm{m}^{2}$, assuming the specific heats of liquid and solid are similar $\Delta G_{\mathrm{v}}$ is the driving force for solidification

$$
\cong \Delta T \Delta S=\frac{\Delta H_{f} \Delta T}{T_{m}},
$$

$\Delta T$ is the undercooling below the liquidus temperature $K$, 
$\Delta S$ the entropy change for liquid to solid phase transformation, $\mathrm{J} / \mathrm{K} / \mathrm{m}^{3}, \Delta H_{\mathrm{f}}$ the enthalpy of solidification and $T_{\mathrm{m}}$ the melting temperature. If the embryo of the solid is greater than critical radius, $r_{\text {homogeneous }}^{*}$, the embryo will survive and become a nucleus.

In heterogeneous nucleation, the critical nucleus size is

$$
r_{\text {heterogeneous }}^{*}=\frac{-2 \gamma_{\mathrm{sL}}}{\Delta G_{\mathrm{v}}}
$$

(1) and (3) are identical for both homogeneous and heterogeneous nucleation and the free energy barrier is

$$
\Delta G_{\text {heterogeneous }}^{*}=\frac{16 \pi \gamma_{\mathrm{sL}}^{3}}{3 \Delta G_{\mathrm{v}}^{2}} f(\theta),
$$

where $f(\theta)$ is a function of the contact angle, $\theta$ on the substrate on which nucleation takes place. Figure 1 shows the solid nucleating on a substrate in a liquid. Figure 2 shows the variation of $f(\theta)$ with $\theta$ and since $f(\theta)$ is always $\leq 1$, the critical free energy for heterogeneous nucleation is always less than or equal to that for homogeneous nucleation. However, it is clear that potent heterogeneous substrates are those with $\theta$ close to zero.

The values of undercooling, $\Delta T$ is of the order $1-2 \mathrm{~K}$ for observable nucleation rates in commercial aluminium alloys with grain refiners. Therefore, clearly heterogeneous nucleation is taking place. The following simplified expression for heterogeneous nucleation rate per unit volume in $\mathrm{m}^{-3} \mathrm{~s}^{-1}$ is

$$
I_{\text {heterogeneous }}^{\mathrm{v}}=10^{18} N_{\mathrm{v}}^{\mathrm{p}} \exp \left[\frac{-16 \pi \gamma_{\mathrm{sL}}^{3} f(\theta)}{3 K_{\mathrm{B}} \Delta S^{2} \Delta T^{2}}\right],
$$

where, $K_{\mathrm{B}}$ is the Boltzmann's constant, $\mathrm{J} / \mathrm{K}, N_{\mathrm{v}}^{\mathrm{p}}$ the number of nuclei $/ \mathrm{m}^{3}$, and $I_{\text {heterogeneous }}^{\mathrm{v}}$ the heterogeneous nucleation rate \# of nuclei $/ \mathrm{m}^{3}$.sec.

Therefore, it can be seen that if contact angle is close to zero, wetting of the substrate for nucleation is promoted and nucleation rate increases.

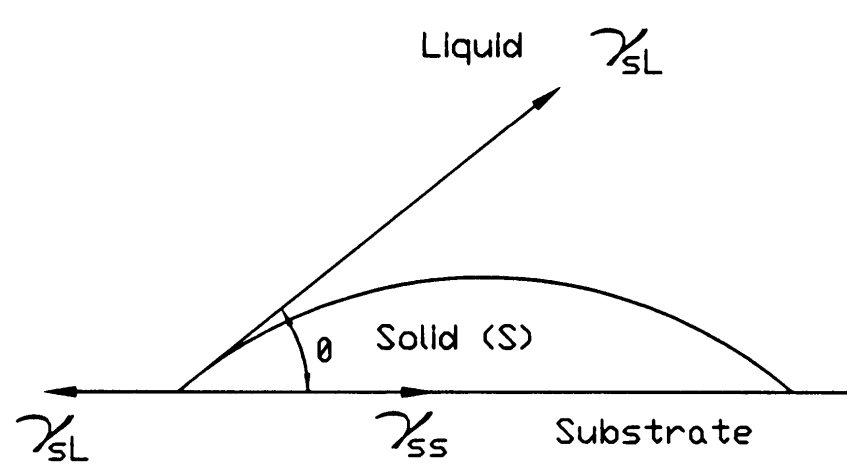

Figure 1. Schematic representation showing the formation of spherical cap of solid (s) on a substrate, contact angle and surface tension forces (McCartney 1989).

\subsection{Growth of nuclei}

Once nucleation takes place, more importantly heterogeneous nucleation, the growth front of the nuclei is seldom planar. The well known constitutional supercooling occurs as solute is rejected at the interface and the criterion is given by (Kurz and Fisher 1984).

$$
\frac{G_{\mathrm{L}}}{R} \geq \frac{-m_{\mathrm{L}} C_{0}(1-k)}{k D_{\mathrm{L}}},
$$

where, $G_{\mathrm{L}}$ is the temperature gradient in the liquid ahead of the solid-liquid interface $(\mathrm{K} / \mathrm{m}), R$ the growth rate of solid liquid interface $(\mathrm{m} / \mathrm{sec}), m_{\mathrm{L}}$ the liquidus slope of phase diagram $(\mathrm{K} / \mathrm{wt} \%), C_{0}$ the bulk alloy composition in the liquid (wt \%), $k$ the partition coefficient between solid and liquid, and $D_{\mathrm{L}}$ the diffusion coefficient of the solute in the liquid $\left(\mathrm{m}^{2} / \mathrm{sec}\right)$.

Normally in a casting we have a columnar zone and a central portion of equiaxed crystals (Flemings 1974a). The columnar dendrites grow in $\left[\begin{array}{lll}1 & 0 & 0\end{array}\right]$ directions in the cubic system and growth direction is antiparallel to the heat flow direction. The equiaxed dendrites grow in the same direction of heat flow i.e. radially outward. The formation of equiaxed crystals is due to dendrite arm melt off (Flemings 1974b) which provides nuclei for equiaxed crystals.

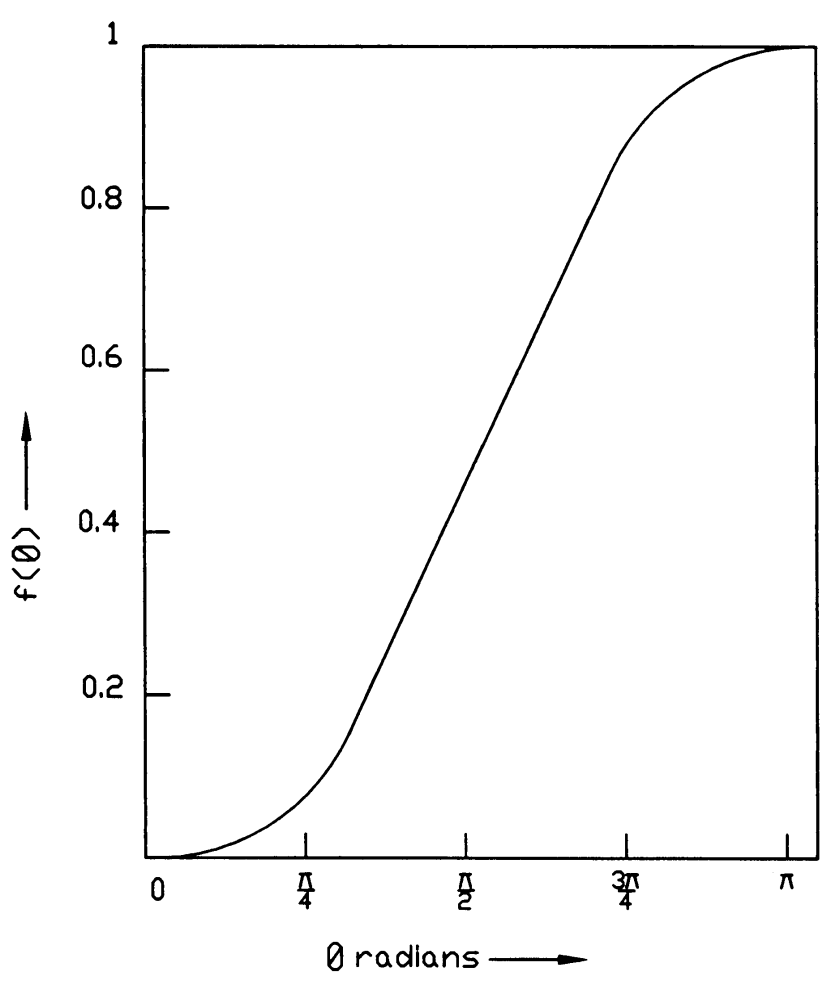

Figure 2. Showing the variation of $f(\theta)$ with $\theta$ where $f(\theta)$ is equal to $\left(2-3 \cos \theta+\cos ^{3} \theta\right) / 4$ (McCartney 1989). 


\subsection{Grain refinement effects}

In industry, both wrought and cast aluminium alloys are grain refined prior to casting. The commonly used grain refiners are commercially available nucleants or master alloys like $\mathrm{Al}-10 \mathrm{Ti}, \mathrm{Al}-5 \% \mathrm{Ti}-1 \mathrm{~B}$ alloys. The efficiency of a grain refiner is assessed by the grain refining curves. Figure 3 (Chandrashekar $\mathrm{T}$ and Kashyap $\mathrm{K} \mathrm{T}$, unpublished work) shows a set of grain refining curves wherein the ordinate is grain size and abscissa is holding time (prior to pouring) for all the above mentioned grain refiners in a Al-7Si-0 $\cdot 3 \mathrm{Mg}(356, \mathrm{LM} 25)$ alloy. It is seen that $\mathrm{Al}-5 \mathrm{Ti}-1 \mathrm{~B}$ (TiBAl) is not very effective when compared to the commercially available nucleants. The reasons for this behaviour will become apparent in the later sections on mechanisms of refinement.

Figure 4 shows the macrostructure of the 356 alloy without any grain refiner. Figures 5 and 6 show the macrostructure of the 356 alloy with the addition of Al-10Ti and $\mathrm{Al}-5 \mathrm{Ti}-1 \mathrm{~B}$ master alloy respectively. The addition rates of these master alloys to the melt are such that there is $0.05 \mathrm{wt} \%$ titanium content in the alloy. Figure 7 shows the macrostructure of the 356 alloy after the addition of commercially available nucleants. Note the drastic reduction in grain size after the addition of grain refiners. Figure 8 shows the scanning electron micrograph of the Al-10Ti master alloy added to the melt indicating the needle morphology of $\mathrm{TiAl}_{3}$. Figure 9 shows the scanning

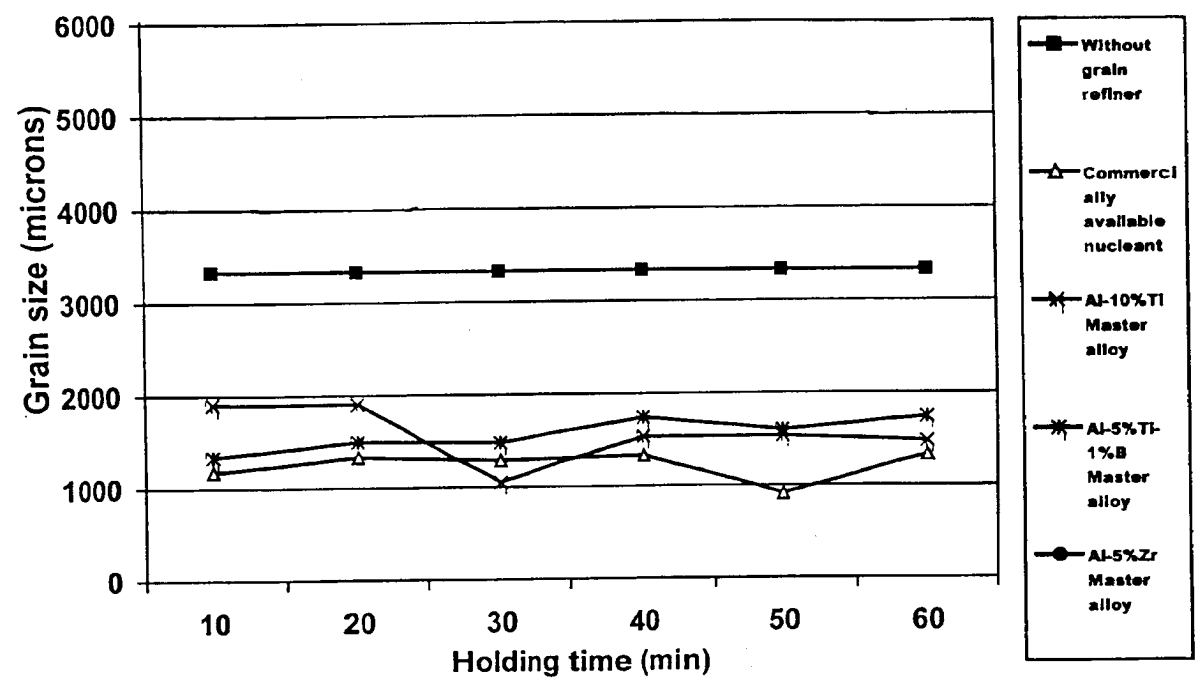

Figure 3. Graph showing grain size vs holding time.

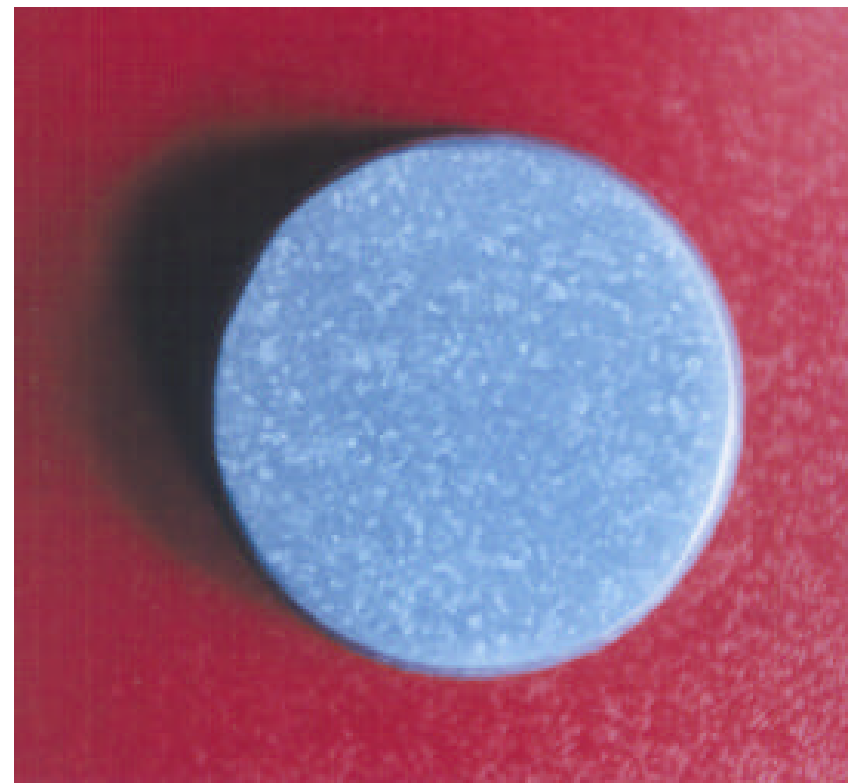

Figure 4. Macrostructure of $\mathrm{Al}-\mathrm{Si}$ (356) alloy without any grain refiner.

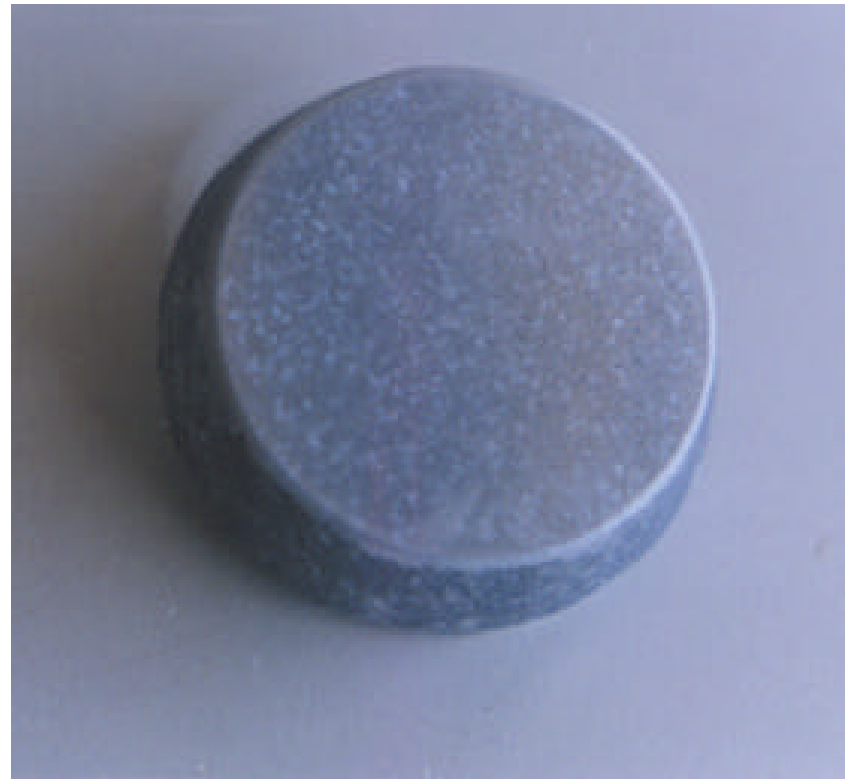

Figure 5. Macrostructure of Al-Si (356) alloy after adding Al-10Ti master alloy. 
electron micrograph of $\mathrm{Al}-5 \mathrm{Ti}-1 \mathrm{~B}$ master alloy indicating the combination of both flaky and blocky morphology of $\mathrm{TiAl}_{3}$. The borides are present at the interface between $\mathrm{TiAl}_{3}$ and $\alpha$-aluminium matrix. Figure 10 shows the microstructure of 356 alloy after grain refinement with Al-5Ti-1B master alloy. Note the fine dendrite arm spacing of the solidified structure. Figure 11 shows the scanning electron micrograph showing the $\mathrm{TiAl}_{3}$ needle on which nucleation of $\alpha$-aluminium is seen to take place.

\section{Nucleant effects in grain refinement}

Way back in 1940s, Cibula (1949) postulated the carbide/ boride theory of grain refinement wherein $\mathrm{TiC}$ and/or

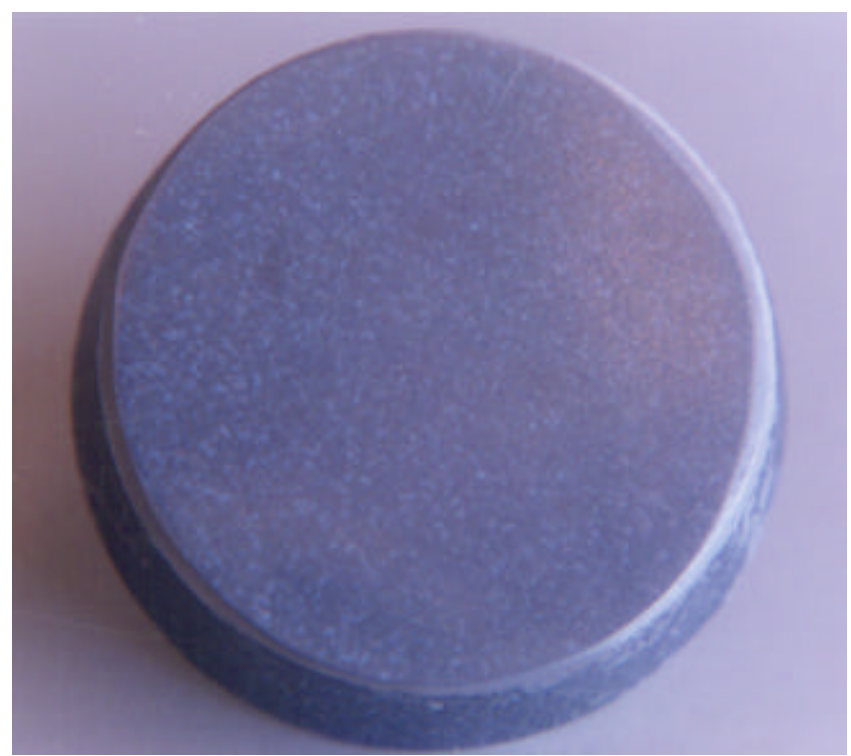

Figure 6. Macrostructure of $\mathrm{Al}-\mathrm{Si}$ (356) alloy after adding Al-5Ti-1B master alloy.

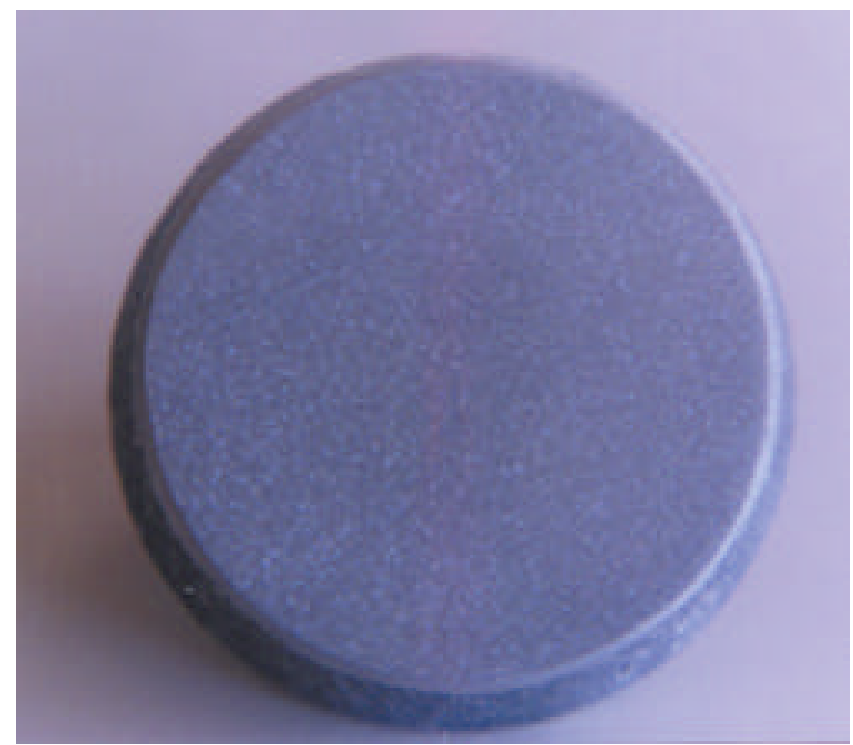

Figure 7. Macrostructure of Al-Si (356) alloy after adding the commercially available nucleants.
$\mathrm{TiB}_{2}$ crystals nucleate solid aluminium by heterogeneous nucleation. Contradicting the above, Crossley and Mondolfo (1951) proposed the peritectic theory where $\mathrm{TiAl}_{3}$ particles in the master alloy nucleate solid aluminium by a peritectic reaction

$$
\mathrm{L}+\mathrm{TiAl}_{3} \rightarrow \alpha \text {-aluminium. }
$$

There has been much debate between these two theories in the literature for the past 50 years (McCartney 1989; Mohanty et al 1995; Easton and St. John 1999).

Borides are added via the master alloy $\mathrm{Al}-\mathrm{Ti}-\mathrm{B}$ and residual carbon reacts with $\mathrm{Ti}$ to form $\mathrm{TiC}$. There is a lot of debate on the stability of $\mathrm{TiC}$ in $\mathrm{Al}$ melts (Fine and Conley 1990; Rapp and Zheng 1991; Banerji et al 1994). Banerji and Reif (1986) have processed Al-Ti-C master alloy for grain refinement of aluminium. The nucleating behaviour of all the borides can be discussed concu-

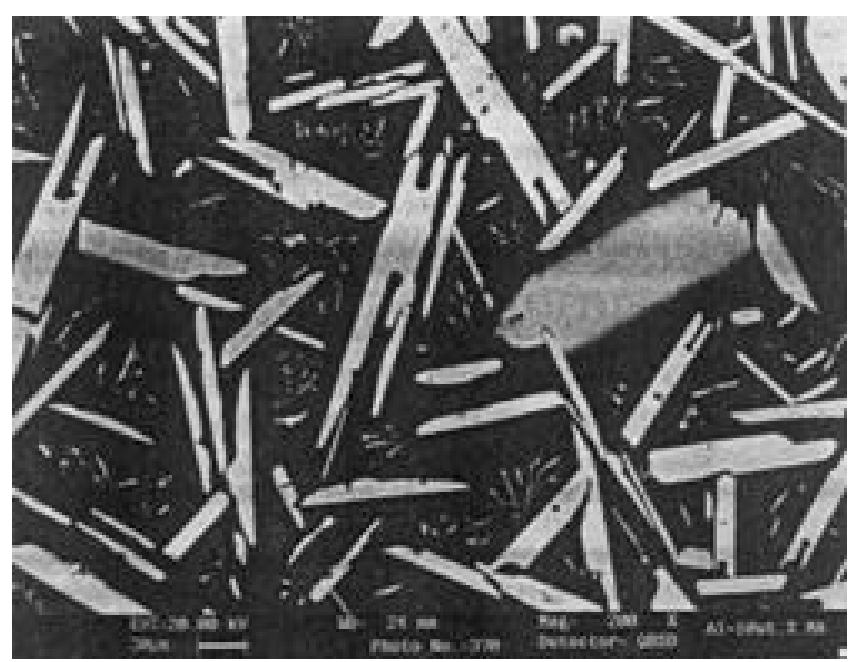

Figure 8. Scanning electron micrograph of Al-10Ti master alloy showing needle morphology of $\mathrm{TiAl}_{3}$.

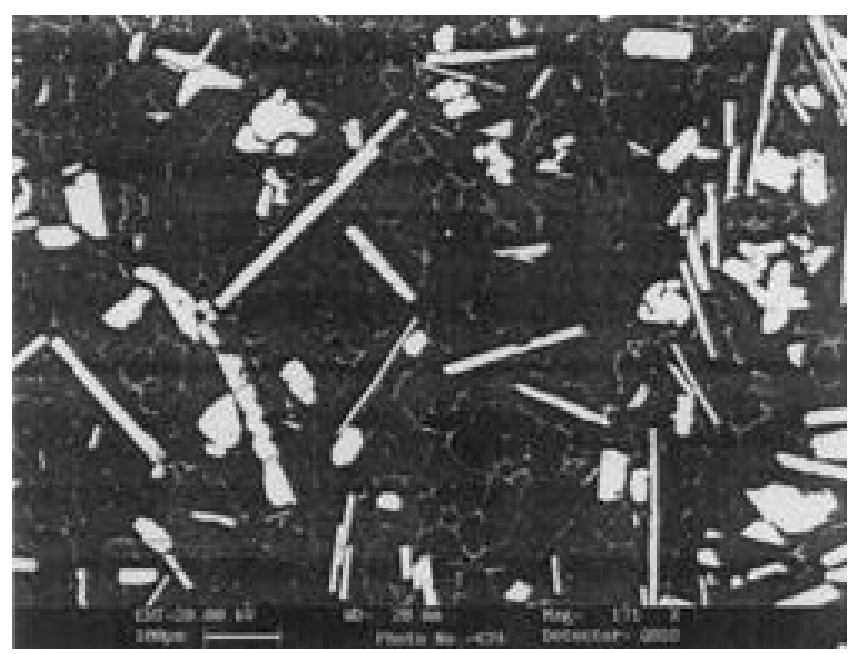

Figure 9. Scanning electron micrograph of Al-5Ti-1B master alloy showing the combination of both flaky and blocky morphology of $\mathrm{TiAl}_{3}$. 
rrently, as $\mathrm{TiB}_{2}$ and $\mathrm{AlB}_{2}$ are isomorphous and hexagonal with lattice parameters, $a=0.30311 \mathrm{~nm}$ and $c=0.32291 \mathrm{~nm}$ and $a=0.3009 \mathrm{~nm}$ and $c=0.3262 \mathrm{~nm}$, respectively (Arnberg et al 1982). The mixed boride phase (Al, Ti) $\mathrm{B}_{2}$ is formed by replacement of titanium atoms by aluminium atoms in the lattice.

When Al-Ti-B master alloy is added so that titanium is present at hypoperitectic levels $(<0 \cdot 15 \% \mathrm{Ti})$ as shown in figure 12 , often boride particles or boride agglomerates are found in the centres of grains, with titanium enriched dendrites growing out of them (Johnsson et al 1993). This evidence suggests that borides nucleate $\alpha-\mathrm{Al}$. But borides were thought to be poor nucleants or at least not as effective as $\mathrm{TiAl}_{3}$ (Guzowski et al 1987). Mohanty et al (1995) have recently confirmed that borides get pushed to the grain boundaries and no grain refinement is observed if no solute titanium is present, which shows that the lattice disregistry between borides and $\alpha$-aluminium is large

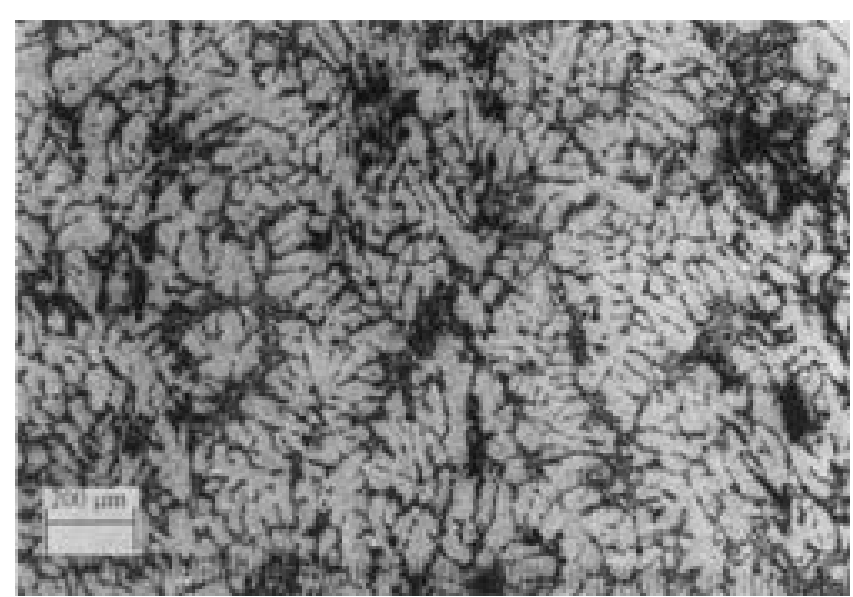

Figure 10. Microstructure of Al-Si (356) alloy after grain refining with Al-5Ti-1B master alloy $(\times 50)$.

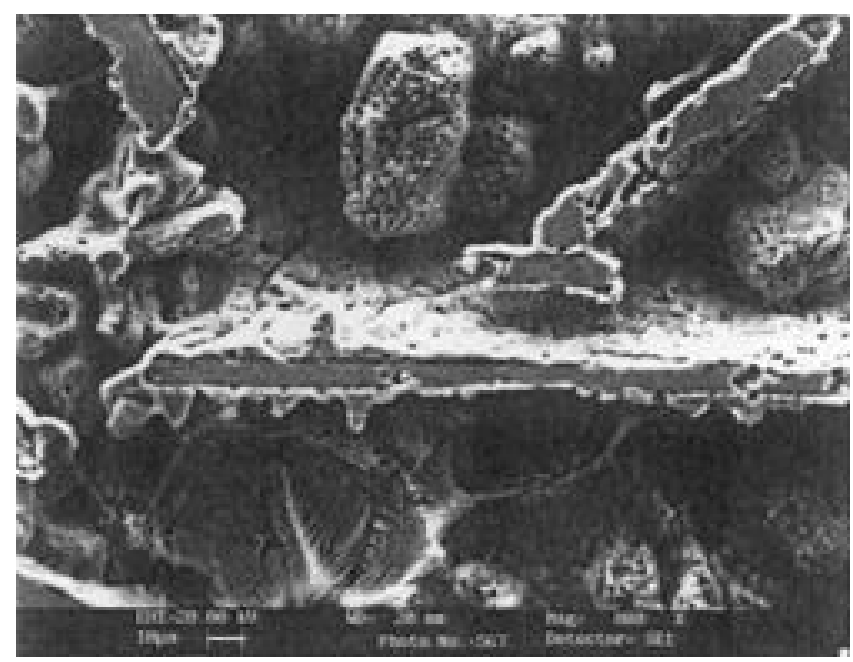

Figure 11. Scanning electron micrograph showing the nucleation of $\alpha$-aluminium on the $\mathrm{TiAl}_{3}$ needle. indicating that borides act as poor nucleant. It is also observed (Maxwell and Hellawell 1972) that the borides need some undercooling while aluminides need none.

In comparison $\mathrm{TiAl}_{3}$ is known to be a powerful refiner. When present at hyperperitectic concentrations, dramatic grain refinement was observed (Crossley and Mondolfo 1951) and also $\mathrm{TiAl}_{3}$ was found at the centres of grains with multiple orientation relationship (Davies et al 1970; Arnberg et al 1982) with Al matrix. From this evidence, it can be concluded that $\mathrm{TiAl}_{3}$ is a better refiner than the $\mathrm{TiB}_{2}$ which is why the phase diagram theories were developed (i.e. by peritectic reaction).

\subsection{Phase diagram theories}

Here in these theories, nucleant particle is taken to be $\mathrm{TiAl}_{3}$. It is suggested that boron addition shifts the peritectic composition $(0.15 \mathrm{wt} \% \mathrm{Ti})$ to smaller levels which according to Marcantonio and Mondolfo (1971) and Mondolfo et al (1988) is $0.05 \%$. This allows $\mathrm{TiAl}_{3}$ to be stable at low titanium levels. Jones and Pearson (1976) and Sigworth $(1984,1986)$ have performed theoretical

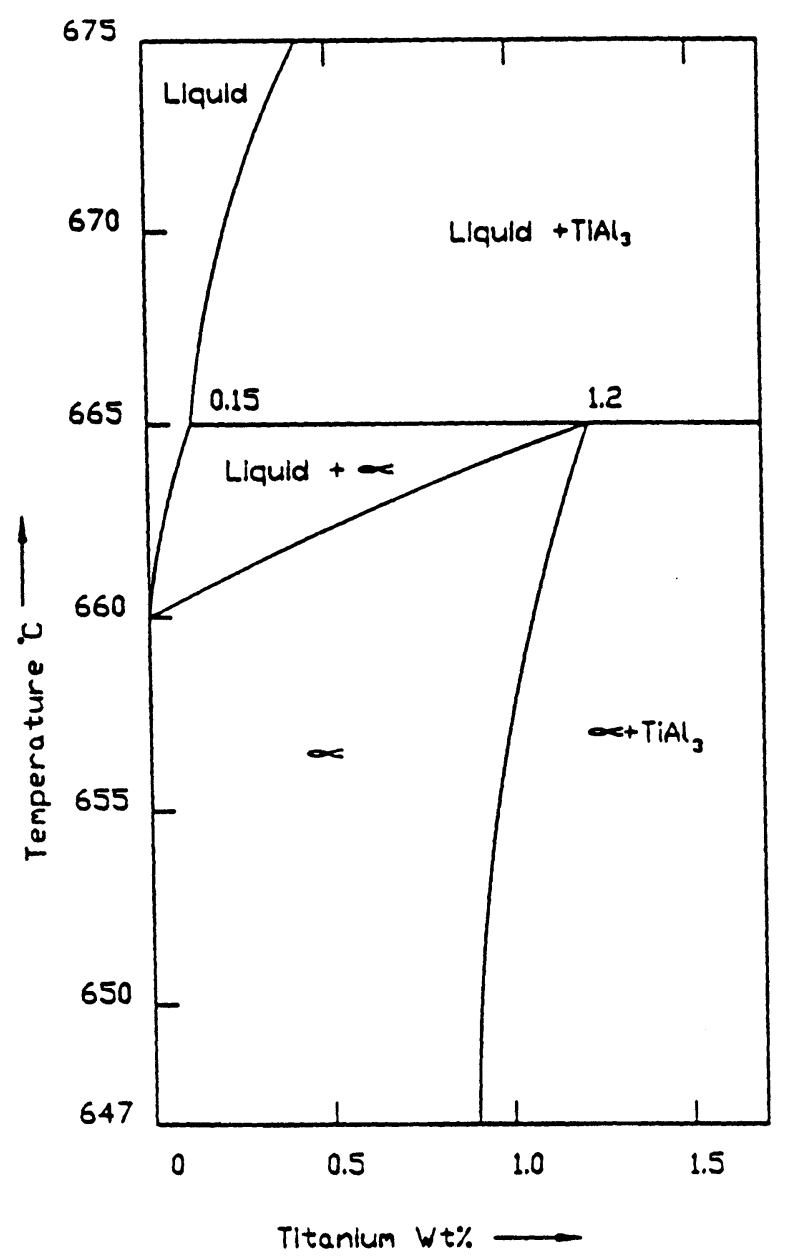

Figure 12. Aluminium end of Al-Ti phase diagram showing $0.15 \% \mathrm{Ti}$ as the peritectic concentration (McCartney 1989). 
thermodynamic calculations and have shown that boron does not alter the Al-Ti phase diagram.

Alternatively it has been argued that $\mathrm{TiAl}_{3}$ crystals from the master alloy are stable at low titanium levels in the melt. It has been shown by several researchers, particularly, Guzowski et al (1987), that the aluminides take about $30 \mathrm{~min}$ to dissolve at $700^{\circ} \mathrm{C}$. This leads to the well known effect known as 'fade' where grain size increases with holding time at the pouring temperature.

Therefore, at low concentrations of titanium $<0.15 \% \mathrm{Ti}$ (peritectic composition), $\mathrm{TiAl}_{3}$ is not stable and will not act as nucleation sites for aluminium.

\subsection{Other theories}

2.2a Peritectic hulk theory: This theory was very popular in the late 1980s and early 1990s supported by Vader and Noordegraaf (1989) and Backerud et al (1991).

This theory assumes that $\mathrm{TiAl}_{3}$ is a powerful nucleant than $\mathrm{TiB}_{2}$. Therefore, it tries to explain how the borides could slow the dissolution rate of $\mathrm{TiAl}_{3}$ when $\mathrm{Al}-\mathrm{Ti}-\mathrm{B}$ master alloy is added to the aluminium melt, so that the more powerful nuclei remain active longer. It suggests that the borides form a shell around the aluminides and hence slow the dissolution of the aluminides as diffusion needs to proceed through the boride shell. The aluminide finally dissolves and leaves a cell of liquid inside the boride shell of approximately the peritectic composition. The peritectic reaction takes place to form $\alpha$-aluminium and growth occurs from there.

Although this theory seems to fit experimental results, but there is strong evidence against it especially by Johnsson et al (1993).

2.2b Hypernucleation theory: This theory was proposed by Jones (1985) and named as such because of the disproportionate effect that very small amounts of titanium and boron make to the grain size of aluminium. Jones (1988) proposes that melt solutes segregate stably to the melt inoculant interface, and in the right conditions stable pseudocrystals can be created above the principal liquidus of the melt, and immediately below the melt liquidus these pseudocrystals allow $\alpha$-aluminium to grow without undercooling. The atomic size of the segregant relative to aluminium is the key factor. Competitive segregation of solutes of mismatching size can 'poison' the otherwise hypernucleative processes.

The main problem with this theory is that there is no experimental evidence.

2.2c Duplex nucleation theory: Of all the mechanisms proposed so far, duplex nucleation theory is the most recent and was first proposed by Mohanty and Gruzleski (1995) and further by Schumacher and Greer (1994a).

Mohanty et al (1995) added synthetic $\mathrm{TiB}_{2}$ particles to the aluminium melt at various titanium concentrations. It was found that $\mathrm{TiAl}_{3}$ layer formed on the $\mathrm{TiB}_{2}$ particles at hyperperitectic concentrations of $\mathrm{Ti}, \alpha$-aluminium was found on $\mathrm{TiAl}_{3}$ layer.

Schumacher and Greer (1994a) added Al-Ti-B grain refiner to an aluminium rich metallic glass of composition $\mathrm{Al}_{85} \mathrm{Ni}_{5} \mathrm{Y}_{8} \mathrm{Co}_{2}$ and also found that borides were surrounded by $\mathrm{TiAl}_{3}$ layer which was further surrounded by $\alpha$-aluminium.

There is a lot of criticism to the duplex nucleation theory particularly by St. John (1990).

Schumacher and Greer (1994b) suggested that an aluminide layer forms in the melt and grows at holding temperatures of $1300^{\circ} \mathrm{C}$. But there is no theoretical reason for this. They suggest that at a superheat of about $740^{\circ} \mathrm{C}$ a stable aluminide layer forms on the surface of $\mathrm{TiB}_{2}$ particles in the melt. At lower superheats of about $370^{\circ} \mathrm{C}$ they found a very thin layer of aluminide. A lot of doubt is cast on this because a high superheat not only preserves a layer of aluminide but also grows at significant holding times. Thus an aluminide layer may form during solidification.

Another major problem with the duplex nucleation theory is that Johnsson and Backerud (1996) measured the nucleation and growth temperatures across the Al-Ti phase diagram for additions of $\mathrm{Al}-5 \% \mathrm{Ti}-1 \% \mathrm{~B}$ master alloy and found that, at hypoperitectic composition, the nucleation temperature follows the Al-Ti liquidus curve. Duplex nucleation theory cannot explain this. The liquid adjacent to $\mathrm{TiAl}_{3}$ needs to be $0 \cdot 15 \% \mathrm{Ti}$ which means that the nucleation temperature should correspond to the nucleation temperature at the peritectic concentration. This means that for an alloy containing $0.05 \% \mathrm{Ti}$ a nucleation temperature of about $3{ }^{\circ} \mathrm{C}$ higher than the liquidus temperature should be present, which the duplex nucleation theory cannot explain.

\section{Solute effects}

Solute elements like titanium segregate to the inoculant/ melt interface and affect the growth of dendrites and also affect the constitutional undercooling at the solid-liquid interface. Though nucleant effects are important, solute effects also play an important role in refinement. Johnsson et al (1993) disputed the earlier wisdom that borides are poor nucleants, but found borides in the centres of grains at hypoperitectic additions of $\mathrm{Al}-\mathrm{Ti}-\mathrm{B}$ master alloy. Johnsson and Backerud (1992) also found that the disregistry of $4.3 \%$ between $\alpha$-aluminium and $\mathrm{TiB}_{2}$ for $\left(\begin{array}{lll}1 & 1 & 1\end{array}\right)_{\mathrm{Al}}\left\|\left(\begin{array}{lll}0 & 0 & 1\end{array}\right)_{\mathrm{TiB}_{2}},\left[\begin{array}{lll}1 & 1 & 0\end{array}\right]_{\mathrm{Al}}\right\|\left[\begin{array}{lll}1 & 1 & 0\end{array}\right]_{\mathrm{TiB}_{2}}$. Although $\mathrm{TiB}_{2}$ does not seem to grain refine without excess titanium, effective refinement occurs when solute titanium is present.

$\mathrm{AlB}_{2}$ particles were known to grain refine aluminium to some extent at concentrations above the Al-B eutectic, i.e. 0.022\%B (Marcantonio and Mondolfo 1971). Tondel (1994) found $\mathrm{AlB}_{2}$ particles in the centre of $\alpha$-grains in hypoeutectic Al-Si alloys. Tondel (1994) also found $\left(\begin{array}{lll}1 & 1 & 1\end{array}\right)_{\mathrm{Al}}\left\|\left(\begin{array}{lll}0 & 0 & 1\end{array}\right)_{\mathrm{TiB}_{2}},\left[\begin{array}{lll}1 & 1 & 0\end{array}\right]_{\mathrm{Al}}\right\|\left[\begin{array}{lll}1 & 1 & 0\end{array}\right]_{\mathrm{AlB}_{2}}$ orientation relationship between $\mathrm{AlB}_{2}$ particles and $\alpha$-aluminium with 
a disregistry of $3 \cdot 5 \%$. $\mathrm{TiB}_{2}$ and $\mathrm{AlB}_{2}$ have similar lattice parameters and are isomorphous, thus confirming the nucleating potency of borides. The mixed borides $\left(\mathrm{Al}_{x}\right.$ $\left.\mathrm{Ti}_{1-x}\right)_{\mathrm{B}_{2}}$ should also be good nucleants.

The segregating power of an element is described by growth restricting factor (GRF) during solidification. The GRF is a measure of the growth restricting effect of solute elements on the growth of solid-liquid interface of the new grains as they grow into the melt. It is defined as $m C_{0}(k-1)$, where $m$ is the liquidus gradient, $C_{0}$ the bulk composition, $k$ the partition coefficient between solid and liquid. Typical values of these parameters for common alloying elements are presented in table 1 .

When a number of solutes are present in the melt, the GRFs are added which assumes that there is no interaction between solutes. GRF for an alloy is $\sum m_{\mathrm{i}}\left(k_{\mathrm{i}}-1\right) C_{0}$.

The criterion for constitutional supercooling is

$$
\frac{G_{\mathrm{L}}}{R} \geq \frac{-\sum m_{\mathrm{i}} C_{0}\left(1-k_{\mathrm{i}}\right)}{k D_{\mathrm{L}}} .
$$

We can see that the growth rate is inversely proportional to $m_{\mathrm{i}} C_{0}\left(k_{\mathrm{i}}-1\right)$. Li et al (1997) have suggested that the reason for grain refinement caused by titanium additions is due to the titanium as a solute. They suggest that the powerful segregating ability of titanium as solute leads to a constitutionally undercooled zone in front of the growing interface within which nucleation can occur on nucleants that are present. Cast alloys are more difficult to grain refine than wrought alloys. The reason for this is thought to be the high level of alloying elements particularly silicon. Al-Ti-B grain refiners with excess titanium have been found to be poor grain refiners. Al-4\% B master alloy is a much effective grain refiner than $\mathrm{Al}-6 \% \mathrm{Ti}$ or $\mathrm{Al}-5 \% \mathrm{Ti}-1 \% \mathrm{~B}$ in casting alloys. Al-Si alloy solidify with an eutectic structure with lamellae of $\alpha$-Al and eutectic silicon. $\mathrm{Na}, \mathrm{Sr}$ are added to the alloy during casting to alter the morphology of the lamellar eutectic silicon to spheroidal form. This is termed as modification. Modification generally improves mechanical properties like ductility and fracture toughness.

When a grain refiner is added to the alloy, there is a critical holding time where the grain size is minimum. Beyond the critical holding time, grain size of the casting increases. This effect is known as 'fade'. Sigworth and Guzowski (1985) developed an Al-3\% Ti-3\%B alloy where $(\mathrm{Al}, \mathrm{Ti}) \mathrm{B}_{2}$ crystals are the nucleant particles present for grain refinement of casting alloys. They found that $\mathrm{AlB}_{2}$ crystals in $\mathrm{Al}-\mathrm{B}$ master alloy dissolve and the fade time to be short. Further they found it to poison $\mathrm{Sr}$ modification whereas Al-3Ti-3B master alloy provides consistent grain refining with little fade and does not poison strontium modification. This shows that solute effects play a dominant role in casting alloys and will be addressed next.

\subsection{Relationship between solute and dendrite growth}

The solute effect of titanium, silicon and iron has been studied by Johnsson (1995) and Johnsson and Backerud (1996). They found that these elements restricted the growth rate of dendrites and are additive in effect which is quantified by GRF. Spittle and Sadli (1995) performed similar experiments with $\mathrm{Al}-5 \mathrm{Ti}-\mathrm{B}$ on a wide range of solute elements and found that grain size dropped dramatically with increase in GRF. Figure 13 shows a graph of grain size vs GRF from Spittle and Sadli's work and also Johnsson's curve.

The data shows that an initial rapid decrease in grain size with GRF is seen and further addition of solute produces no effect but after a GRF value of 20 the grain size began to increase.

The solute effect of silicon produces grain refinement at about $3 \mathrm{wt} \%$, while titanium only needs to be added at concentration of about $0 \cdot 1 \mathrm{wt} \%$ for optimum grain refin-

Table 1. Segregating power of some elements in aluminium (Easton and St. John 1999).

\begin{tabular}{|c|c|c|c|c|c|}
\hline Element & $k_{\mathrm{i}}$ & $m_{\mathrm{i}}$ & $\left(k_{\mathrm{i}}-1\right) m$ & $\begin{array}{c}\text { Maximum } \\
\text { concentration } \\
(\mathrm{wt} \%)\end{array}$ & $\begin{array}{c}\text { Reaction } \\
\text { type }\end{array}$ \\
\hline $\mathrm{Ti}$ & $\sim 9.0$ & $30 \cdot 7$ & $245 \cdot 6$ & $15 \cdot 00$ & Peritectic \\
\hline $\mathrm{Ta}$ & $2 \cdot 5$ & $70 \cdot 0$ & $105 \cdot 0$ & $\sim 0 \cdot 10$ & Peritectic \\
\hline V & $4 \cdot 0$ & $10 \cdot 0$ & $30 \cdot 0$ & $\sim 0 \cdot 10$ & Peritectic \\
\hline $\mathrm{Hf}$ & $2 \cdot 4$ & $8 \cdot 0$ & $11 \cdot 2$ & $\sim 0.50$ & Peritectic \\
\hline Mo & $2 \cdot 5$ & $5 \cdot 0$ & $7 \cdot 5$ & $0 \cdot 10$ & Peritectic \\
\hline $\mathrm{Zr}$ & $2 \cdot 5$ & $4 \cdot 5$ & $6 \cdot 5$ & $\sim 0.11$ & Peritectic \\
\hline $\mathrm{Nb}$ & $1 \cdot 5$ & $13 \cdot 3$ & $6 \cdot 6$ & $\sim 0 \cdot 15$ & Peritectic \\
\hline $\mathrm{Si}$ & $0 \cdot 11$ & $-6 \cdot 6$ & $5 \cdot 9$ & $\sim 12.60$ & Eutectic \\
\hline $\mathrm{Cr}$ & $2 \cdot 0$ & $3 \cdot 5$ & $3 \cdot 5$ & $\sim 0.40$ & Peritectic \\
\hline $\mathrm{Ni}$ & 0.007 & $-3 \cdot 3$ & $3 \cdot 3$ & $\sim 6.00$ & Eutectic \\
\hline $\mathrm{Mg}$ & $0 \cdot 51$ & $-6 \cdot 2$ & $3 \cdot 0$ & $\sim 3.40$ & Eutectic \\
\hline $\mathrm{Fe}$ & $0 \cdot 02$ & $-3 \cdot 0$ & $2 \cdot 9$ & $\sim 1.80$ & Eutectic \\
\hline $\mathrm{Cu}$ & $0 \cdot 17$ & $-3 \cdot 4$ & $2 \cdot 8$ & $33 \cdot 20$ & Eutectic \\
\hline Mn & $0 \cdot 94$ & $-1 \cdot 6$ & $0 \cdot 1$ & 1.90 & Eutectic \\
\hline
\end{tabular}


ing effectiveness. These are equivalent GRFs (i.e. $17 \cdot 7$ for $3 \mathrm{wt} \% \mathrm{Si}$ and 24.5 for $0.1 \% \mathrm{Ti}$ ).

According to Johnsson and Backerud (1996), the grain size begins to increase once again above a critical value, due to a change in the growth mechanism of dendrites. At low GRFs solute slows down growth of the dendrite, due to diffusion of solute in front of the interface. But at higher concentrations, the dendrites develop lancet like tips which grow into the liquid and reject solute orthogonally to the growth direction. This is due to the change from diffusion controlled growth, to dendrite tip radius controlled growth, where capillary effects dominate.

In the recent work of Spittle et al (1997) in Al-Zn system, there was no increase of grain size after the minimum, as more solute was added. Solute was added up to a GRF of 50. This is very different from Johnsson's (1996) $\mathrm{Al}-\mathrm{Si}$ alloys. Therefore solute effect depends on the system also.

Further research is needed to understand the solute effects particularly interaction between solutes and their effect on GRF.

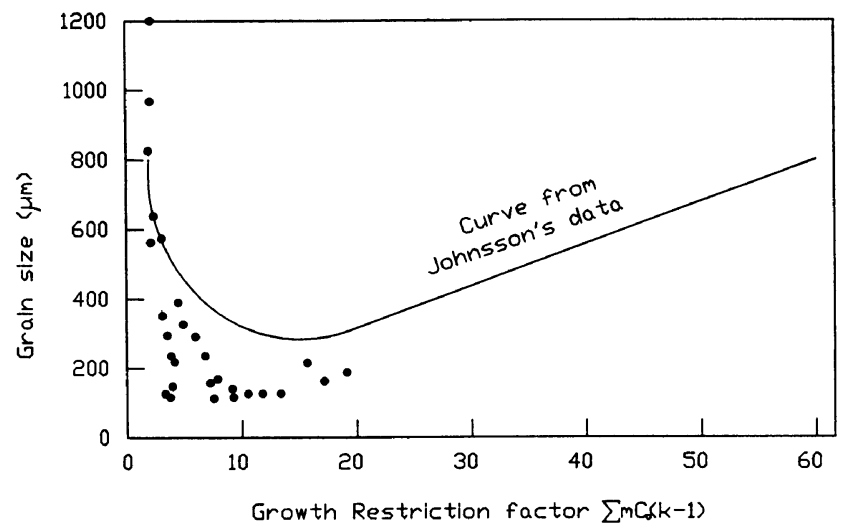

Figure 13. Graph of grain size data plotted against the growth restricting factor (GRF) (Easton Mark and St. John David 1999).
Kearns et al (1996) analysed the grain size data of various wrought aluminium alloys and related the same to the constitutional undercooling parameter.

$$
\frac{G_{\mathrm{L}}}{R} \geq \frac{-m_{\mathrm{L}} C_{0}(1-k)}{k D_{\mathrm{L}}},
$$

which is proportional to GRF. They calculated constitutional undercooling parameter for various alloying additions and showed that for identical parameters, grain size was the same in cases where solutes did not interact to form intermetallic compounds. Recently, Easton and St. John (1999) have shown that in Al-2Si and Al-0.05\% Ti, addition of $\mathrm{TiB}_{2}$ particles refines the grain size to the same extent. Both $\mathrm{Al}-2 \mathrm{Si}$ and $\mathrm{Al}-0.05 \% \mathrm{Ti}$ have the same GRF. However, recently, Easton and St. John (1999) have shown that the measured partition coefficient ' $k$ ' for Ti is 6.7 compared with phase diagram prediction of 7.5 in pure $\mathrm{Al}$ and $3 \cdot 2$ for $\mathrm{Ti}$ in $\mathrm{Al}-7 \mathrm{Si}-0 \cdot 3 \mathrm{Mg}$ alloy.

The low partition coefficient of $\mathrm{Ti}$ in $\mathrm{Al}-\mathrm{Si}$ alloys is seen to be responsible for the poor grain refining effectiveness of titanium.

The partition coefficient of $\mathrm{Ti}$ in pure $\mathrm{Al}$ is 7.5 whereas it is only $3 \cdot 2$ in $\mathrm{Al}-7 \mathrm{Si}-0 \cdot 3 \mathrm{Mg}$ alloy. The growth restricting factor is given by $m C_{0}(k-1)$ which would be large in $\mathrm{Al}$ and low in $\mathrm{Al}-7 \mathrm{Si}-0 \cdot 3 \mathrm{Mg}$ alloy. Therefore, the constitutional undercooling in high purity aluminium would be larger when compared to $\mathrm{Al}-7 \mathrm{Si}-0 \cdot 3 \mathrm{Mg}$ cast alloy. Therefore, the solute effect of titanium would be greater in high purity aluminium than in $\mathrm{Al}-7 \mathrm{Si}-0 \cdot 3 \mathrm{Mg}$ alloy.

To summarize, the solute effect is shown in figure 14 where the constitutional undercooling zone is shown in front of a growing dendrite tip. If the GRF factor for a solute is large, this undercooled zone will be large. If nucleant particles are present in sufficient number (like $\mathrm{AlB}_{2}, \mathrm{TiB}_{2}$ etc), these particles nucleate $\alpha$-aluminium in the supercooled zone. This process repeats itself leading to a very fine grain size. Here it is seen that the $\mathrm{TiAl}_{3}$ layer on borides as shown by Schumacher and Greer

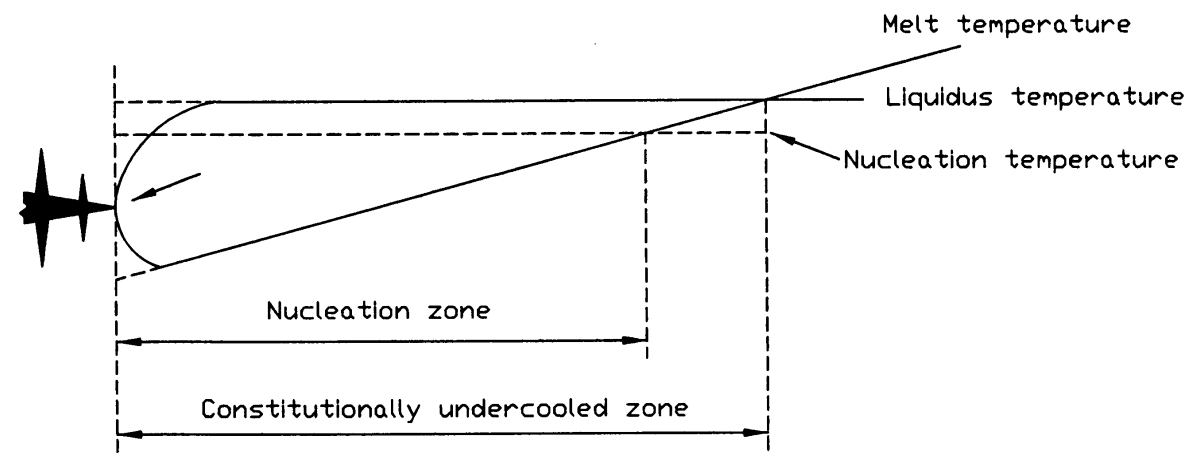

Figure 14. Diagram showing constitutionally undercooled region in front of a growing dendrite and the zone in which nucleation can occur, if nucleant particles are present. The size of this zone will change depending on the potency of the nucleant and the constitution of the melt. If $\mathrm{Ti}$ is present the size of the undercooled zone will increase (Easton Mark and St. John David 1999). 
(1994b) and Mohanty et al (1995) may be inconsequential for grain nucleation.

The duplex nucleation theory of Schumacher and Greer (1994b) and Mohanty and Gruzleski (1995) wherein a titanium aluminide layer is believed to form on borides wherein by peritectic reaction nucleation of $\alpha$-Al would take place on the borides. This would be inconsequential in the light of solute effects of dissolved titanium. Both the above works had excess titanium dissolved in $\mathrm{Al}$ which would lead to a high GRF.

The above grain refinement during solidification has a solid state counterpart wherein zirconium is added to aluminium alloys. Zirconium forms $\mathrm{ZrAl}_{3}$ particles during solidification and/or by heat treatment. The $\mathrm{ZrAl}_{3}$ particles are fine particles of the order of $100 \mathrm{~nm}$ and structure is cubic ordered $L 1_{2}$ phase with a lattice parameter of $0.408 \mathrm{~nm}$. These particles pin the grain boundaries during recrystallization and grain growth in commercial aluminium alloys. A fine grained alloy is obtained which is found to be superplastic in some situations.

\section{Conclusions}

(I) Grain refinement of aluminium alloys is by heterogeneous nucleation and growth of grains.

(II) Nucleating effects in grain refinement are important but solute effect plays a vital role in refinement.

(III) The segregating power of $\mathrm{Ti}$ is very high and it segregates to the nucleant-liquid interface which leads to constitutional supercooling within which other nucleant particles get activated for nucleation.

(IV) Of all the nucleant effects, the Duplex nucleation theory i.e. $\mathrm{TiAl}_{3}$ layer forming on boride particle may be inconsequential as solute $\mathrm{Ti}$ is required to activate nucleation.

\section{References}

Apelian D, Sigworth G K and Whaler K R 1984 Trans. AFS 92 297

Arnberg L, Backerud L and Klang H 1982 Met. Technol. 97

Backerud L, Gustafson P and Johnsson M 1991 Aluminium 67910

Banerji A and Reif N 1986 Metall. Trans. A17 2127

Banerji A and Reif W 1987 Solidification processing (London: The Inst. of Met.) p. 145

Banerji A, Reif W and Feng Q 1994 J. Mater. Sci. 291958

Cibula A 1949 J. Inst. Met. 76321

Cibula A 1951 J. Inst. Met. 8016

Crossley F A and Mondolfo L F 1951 Trans. AIME 1911143

Davies I G, Dennis J M and Hellawell A 1970 Metall. Trans. 1 275

Easton Mark and St. John David 1999 Metall. Mater. Trans. A30 1613

Fine M E and Conley J G 1990 Metall. Trans. A21 2609

Flemings Merton C 1974a Solidification processing (eds) M Stephen et al (USA: McGraw-Hill Inc.) ch. 5, p. 135
Flemings Merton C 1974b Solidification processing (eds) M Stephen et al (USA: McGraw-Hill Inc.) ch. 5, p. 151

Granger D A 1985 Proc. int. seminar on refining and alloying of liquid aluminium and ferro-alloys (Norway: Trondheim) p. 231

Granger D A and Liu L 1983 J. Met. 3554

Guzowski M M, Sigworth G K and Sentner D A 1987 Metall. Trans. A18 603

Johnsson M 1993 Light metals (ed.) S K Das (Warrendale, PA: TMS) p. 769

Johnsson M 1995 Thermochimica Acta 256107

Johnsson M and Backerud L 1992 Z. Metallkd. 83774

Johnsson M and Backerud L 1996 Z. Metallkd. 87216

Johnsson M, Backerud L and Sigworth G K 1993 Metall. Trans. A24 481

Jones G P 1985 Int. sem. on refining and alloying of liquid Al and ferro-alloys (eds) T A Engh et al (Dusseldorf: Aluminium Verlag, Norway, Trondhiem) p. 213

Jones G P 1988 in Proc. conf. solidification processing 1987 (eds) J Beech and H Jones (London: The Institute of Metals) p. 496

Jones G P and Pearson J 1976 Metall. Trans. B7 223

Kearns M A, Thistlewaite and Cooper P S 1996 Light Metals 713

Kurz W and Fisher D J 1984 Fundamentals of solidification (Switzerland: Trans. Tech. Publications) p. 47

Labarri L C, James R S, Witters J J, O' Malley R J and Emptage M R 1987 J. Phys. (Orsay) 48 C3 Suppl. 93

Li H, Sritharan T, Lam Y M and Leng N Y 1997 J. Mater. Sci. Technol. 66253

Marcantonio J A and Mondolfo L F 1971 Metall. Trans. 2465

Maxwell I and Hellawell A 1972 Metall. Trans. 31487

McCartney D G 1989 Int. Mater. Rev. 34247

Mohanty P S, Samuel F H, Gruzleski J E and Kosto T J 1994 Light metals (ed.) U Manweiler (Warrendale, PA: TMS) p. 1039

Mohanty P S and Gruzleski J E 1995 Acta Metall. Mater. 43 2001

Mohanty P S, Samuel F H and Gruzleski J E 1995 Metall. Mater. Trans. B26 103

Mondolfo L F, Farooq S and Tsc C 1988 Solidification processing 1987 (London: The Inst. of Metals) p. 133

Rapp R A and Zheng X 1991 Metall. Trans. A22 3071

Schumacher P and Greer A L 1994a Mater. Sci. Eng. A178 309

Schumacher P and Greer A L 1994b Mater. Sci. Eng. A181 1335

Sigworth G K 1984 Metall. Trans. A15 277

Sigworth G K 1986 Metall. Trans. A22 349

Sigworth G K and Guzowski M M 1985 AFS Trans. 172907

Spittle J A and Sadli S 1995 Mater. Sci. Technol. 11533

Spittle J A, Keeble J M and AlMeshedani M 1997 Light metals (ed.) R Huglen (Warrendale, PA: TMS) p. 795

St. John D H 1990 Acta Metall. Mater. 38631

Tondel P A 1994 Grain refinement of hypoeutectic Al-Si foundry alloys, Ph.D. Thesis, The University of Trondheim, Trondheim

Vader M and Noordegraaf J 1989 Light metals (ed.) P G Campbell (Warrendale, PA: TMS) p. 937

Vader M and Noordegraaf J 1990 Light metals (ed.) C M Bickert (Warrendale, PA: TMS) p. 851

Volmer M and Weber A 1925 Z. Krift. Phys. Chem. 119277 